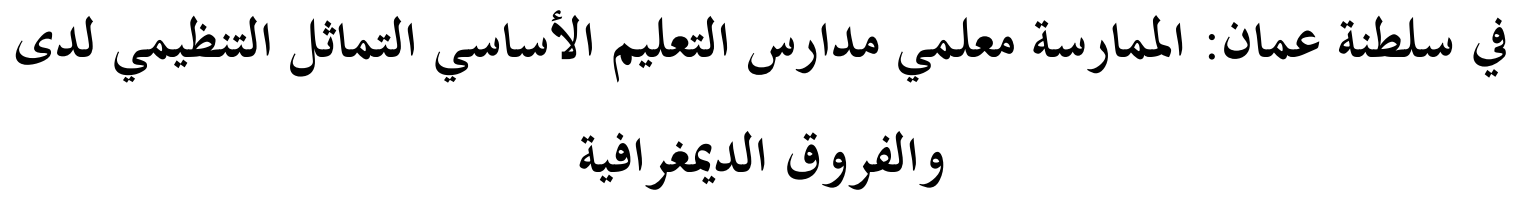

\title{
Organizational Identification (OI) among Basic Education School Teachers in Oman: Prevalence and Demographic Differences
}

\author{
Said Rashid Ali Alshuhumi \\ Ministry of Higher Education, \\ Sultanate of Oman, \\ Oman \\ said.alshahome@moe.om
}

\author{
Dawood Abdulmalek AlHidabi \\ Kulliyyah of Education, \\ International Islamic University Malaysia, \\ Kuala Lumpur, Malaysia \\ dawood@iium.edu.my
}
Abdulmajid Mohammed Abdulwahab
Aldaba
Kulliyyah of Education, International Islamic University Malaysia, Kuala Lumpur, Malaysia
drmajid@iium.edu.my




$$
\begin{aligned}
& \text { مُلَّْص البحث } \\
& \text { هدفت الدراسة المى التعرف على مستوى التماثل التنظيمي لدى معلمي مدارس التعليم الاساسي في سلطنة } \\
& \text { عمان واستقصاء الفروق لبعض المتغيرات الديمغرافية. لتحقيق أهداف الدراسة، تم تبني المنهج الوصفي } \\
& \text { المسحي واستخدام مقياس مستوى التماثل التنظيمي بعد التأكد من صدقه وثباته. وزع المقياس لعينة طبقية } \\
& \text { عشوائية تكونت من } 1 \text { ـ معلم ومعلمة. تم استخدام الإحصاء الوصفي ( المتوسطات الحسابية والانحرافات } \\
& \text { المعيارية) لتحديد مستوى التماثل التنظيمي لدى أفراد العينة، وكذلك الإحصاء الاستدلالي (اختبار ت } \\
& \text { للعينات المستقلة واختبار تحليل التباين الأحادي) لتحديد الفروق الاحصائية ذات الدلالة في مستوى } \\
& \text { التماثل التنظيمي حسب متغيرات ديموقرافية. وقد أظهرت النتائج أن مستوى التماثل التنظيمي لدى عينة } \\
& \text { الدراسة مرتفع، و وجود فروق دالة في المستوى يعزى لمتغير النوع الاجتماعي؛ ولم تظهر فروق في مستوى } \\
& \text { التماثل التنظيمي لمتغيري المؤهل والخبرة، تقدم هذه الدراسة مجموعة من التوصيات لوزارة التربية والتعليم } \\
& \text { العمانية تهدف إلى تعزيز التماثل التنظيمي لدى معلمي المدارس والذي بدوره سيُساعد في تحسين الاداء } \\
& \text { الملدرسي. } \\
& \text { الكلمات المفتاحية: لتماثل التنظيمي ، معلمي مدارس التعليم الأساسي، سلطنة عمان }
\end{aligned}
$$

\begin{abstract}
This paper reports on a systematic review of the empirical research related to the concept of wisdom, its components, and measurement tools. The review encompassed a total of thirty $(\mathrm{N}=30)$ research papers published in refereed databases and journals. Based on the inclusion criteria, some 206 papers were identified and from this list, 30 research papers that met the criteria were accepted for the analysis. The results showed that despite the variations existing in the conceptualizations of wisdom, a great similarity was found in its definitions and components across the 30 studies that were reviewed. Across studies, it was discovered that self-reports and benchmarking are the most common and reliable measurement tools of wisdom. The study recommended further clarification and search for wisdom across diverse samples as well as the development of multi-modal assessment tools that are theoretically and psychologically valid to enhance the rigorous scientific study of this complex construct of wisdom.
\end{abstract}

Keywords: Organizational identification, basic education, gender differences, demographic differences, Omani school teachers 


\section{مُقِلِمِة}

تعد المدرسة أحد أهم المؤسسات التعليمية الخدمية، بوصفها مؤسسة تربوية وثقافية واجتماعية، تضطلع بدور حيوي وهام في إعداد الأفراد، وتربية النشء وتزويدهم بالمعارف المختلفة وإكسابمم القيم الإيجابية والمهارات اللازمة للنهوض بمستوى أدائهم، وإعدادهم للقيام بتحمل واجباقم ومسؤولياقم المستقبلية بجاه مجتمعهم ووطنهم، حيث يعتمد تقدم المجتمعات وتطورها، بناءً على فاعلية المؤسسات التربوية، ونوعية برابجها وخدماتَا التربوية، وجودة مخرجاتما التعليمية. إن أي مؤسسة لا يمكن أن تحقق أهدافها بكفاءة وفاعلية، ما لم تتوافر فيها قيادة ناجحة تتمتع بقدرات وإمكانات تؤهلها للقيام بأدوارها في عمليات التخطيط والتنفيذ والإشراف والتجديد، لذا فإن نجاح المؤسسات التربوية يعتمد على مدى نجاح وفعالية القيادة المدرسية. حيث يعد القائد المدرسي العمود الأساسي الذي يقوم عليه كيان المؤسسة التربوية ومستقبلها، والمحرك الرئيسي لطاقاها وإمكاناقا البشرية والمادية من أجل بلوغ الأهداف التربوية المخطط لها، كما يعد مدير المدرسة المسؤول الأول الذي يقع على قمة الهرم المدرسي، والذي أنيط به تحمل قيادة هذه المؤسسة لتحقيق آمال وتطلعات العاملين وأفراد المجتمع المحيط (الزعبي، با.ب). وفي إطار الاهتمام بالمؤسسات عامة، ظهرت عدة مصطلحات تنظيمية في ججال الفكر السلوكي والإداري، ومن بين المصطلحات الناشئة التي برزت مؤخرًا بشكل لافت للنظر في نصوص وأدبيات الفكر الإداري والإدارة التربوية، مصطلح التماثل التنظيمي (Krso, 2017). ويعد مصطلح التماثل التنظيمي، من المفاهيم الحديثة نسبيًا في مجال الإدارة، حيث بدأ الاهتمام به يتزايد منذ النصف الثاني من القرن الماضي، وأولى الباحثون اهتمامًا كبيرً في ضوء ما تقوم به المنظمات من أدوار ومهام جسام في خدمة الأفراد وتطور المجتمعات، وتعد جماعة العمل مرتكزًا اساسيًا في تحقيق نجاحها، ومن هنا بدأت المؤسسات تعمل جاهدةً Johnson, ) على أن يؤمن العاملون فيها برؤية وأهداف المؤسسة، وأن تتلاقى أهدافهم مع أهداف مؤسساةم 1999 بالمنظمة نفسيًا واجتماعيًا، ويشعر بأنه جزء منها وأن أهدافه وقيمه تتطابق مع أهداف وقيم المنظمة (Cheney,1983). ويعرف أيضًا بأنه إدراك الفرد ومعرفته بأنه متحد مع المنظمة التي ينتمي إليها ومرتبط بها، الأمر الذي يدفعه إلى التعريف عن نفسه بأنه جزء منها (Ashforth \& Mael, 1989). بينما أشار رشيد

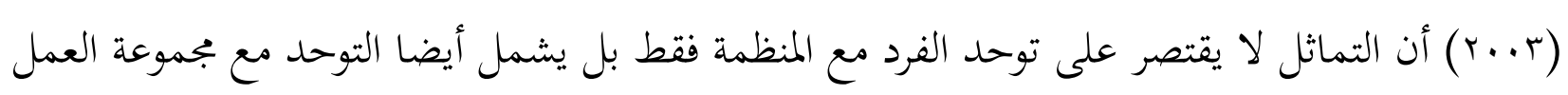


حيث يعرف الأفراد أنفسهم من خلال الخصائص التي تعرف بها المجموعة أو المنظمة (مركزية، متميزة، مستمرة) ويستمد الفرد منها مفهومه الذاتي. ولتحقيق مبدأ التماثل لدى الموظفين بحاه منظماةم يجب أن يشعر الفرد بوجود ثلاثة عناصر مهمة تعد بمثابة أبعاد رئيسة للتماثل التنظيمي هي (1) الولاء التنظيمي (Organization Loyalty) ويعبر عن ولاء الفرد للمنظمة والدعم والحماس لتحقيق أهدافها والدفاع عنها ومحاكاة سلوك الأعضاء الآخرين بها. (r) التشابه التنظيمي (Organization similarity) ويعبر عن إدراك الفرد لوجود خصائص وقيم وأهداف مشتركة مع الأعضاء الآخرين في المجموعة أو المنظمة التي يعمل فيها. (r) العضوية (Membership) وهو درجة مفهوم الفرد لذاته من حيث ارتباطه بالمنظمة، وإحساسه بالانتماء وشعوره الشديد بالالتصاق والجاذبية النفسية معها، وتعريف الذات من خلال عضويته بالمنظمة Cheney,1983)). وحول أهمية التماثل التنظيمي أشار كثير من الباحثين إلى أنه يسهم في تقديم المصلحة العامة على المصلحة الشخصية، وزيادة شعور الفرد بالارتباط النفسي مع المنظمة، المصير المشترك، إضافة إلى الشعور بالارتياح في العمل والرغبة في البقاء في المنظمة وبذل أقصى الجهود لتحسين أداء المنظمة وتحقيق أهدافها (رشيد،r...r)، كما يسهم التماثل في زيادة مستوى الولاء والإخلاص والالتزام والتعاون، والمحافظة على سمعة المنظمة والدفاع عن مصالحها، تحسين مكانة المنظمة، إحداث التغيير المطلوب، إضافة إلى أن التماثل يؤثر إيجابا في ابحاهات العاملين وسلوكياةم واعتقاداتم (البشابشة،^...r). كما يعزز التماثل من احترام Mael ( الذات، والسمو فوقها، وإضفاء معنى للحياة العامة، وزيادة مستوى الطموح والانتماء بتحاه المنظمة Ashforth,2001)، والتقليل من ضغوط العمل، انخفاض مستوى الصراع التنظيمي، زيادة معدلات الرضا الوظيفي والولاء والدافعية نحو العمل، مما ينعكس إيجابا على الأداء العام للمنظمة (العاني والبكري، VI. r). ونظرا لأهمية التماثل التنظيمي على مستوى الأفراد والمنظمات، فقد اهتمت كثير من الدراسات العربية والأجنبية بهذا الموضوع، حيث أجرى ميل وآشفورث (Mael \& Ashfortth, 1992)، دراسة لتختبر أنموذج مقترح للهوية التنظيمية مطبقة على عينة مكونة من (Y Y ) من الذكور خريجي أحد الكليات الدينية بشمال الولايات المتحدة، وأظهرت نتائج الدراسة أن التماثل التنظيمي يتأثر ببعض المتغيرات مثل الرضا الوظيفي، والتميز التنظيمي، والهيبة التنظيمية، ومدة الخدمة، والعاطفة. إضافة إلى ذلك، قد يأتي أيضًا من عوامل أخرى مثل: المركز التنظيمي للفرد في المنظمة، وحداثة العضوية في المنظمة. كما أجرى باسرا وياسوري 
(Basara \& Syory,2015 ) للمعلمين العاملين في المدارس الابتدائية والثانوية في مدينة كانيكا في العاصمة أنقرة بتركيا، وطبق الباحث الاستبانة على عينة مكونة من ( Y Y ) معلما، وأظهرت نتائج الدراسة وجود تأثير إيجابي للعدالة التنظيمية في التماثل التنظيمي، وان مستوى التماثل التنظيمي لدى المعلمين جاء بدرجة متوسطة. واثبتت دراسة ميت وآخرون (Mete, Sökmen, \& Biyik, 2016) والتي أجريت على ( (I ) من الموظفين في قطاع تكنولوجيا المعلومات في القطاع الحكومي التركي، عن وجود علاقة تبادلية بين الرضا الوظيفي والتماثل التنظيمي، كذلك فإن العلاقة التبادلية بين الرضا الوظيفي والتماثل التنظيمي محكن أن تؤثر تأثيرًا مباشرًا على الالتزام الوظيفي ومدى مناسبة الشخص للمؤسسة، و تأثير غير مباشر لكل عامل بوسيط العامل الآخر . أما دراسة ركزت على اختبار التأثير المباشر لتماثل الطالاب مع (El-Kassar, Makki, \& Gonzalez-Perez, 2019) جامعاكم على ولائهم للجامعة، وأجريت الدراسة على عينتين من جامعتين مختلفتين الأولى الجامعة اللبنانية الأمريكية في لبنان، والثانية جامعة جامعة EAFIT في كولومبيا، وتضمنت العينة الأولى (وبء) طالبًا من طلاب الجامعة اللبنانية الأمريكية، بينما العينة الثانية تكونت من (.9. (19) طالبًا من جامعة EAFIT في كولومبيا، ووصل إجمالي حجم العينة (9/7) طالبًا من الجامعتين، وأظهرت النتائج وجود تأثير لتماثل الطلاب مع جامعاهم وبين ولائهم للجامعة، وقيام التماثل بدور الوساطة بين مسؤولية الجامعة الاجتماعية وولاء الطلاب لجامعاتم. من ناحية أخرى، تناولت بعض الدراسات العربية موضوع التماثل التنظيمي، فقد كانت أول دراسة عربية للباحث رشيد (r..r)، وهدفت إلى إلقاء الضوء على مفهوم الهوية التنظيمية والتماثل التنظيمي، لدى أعضاء هيئة التدريس في جامعة الملك سعود بالمملكة العربية السعودية مع الجامعة وأقسامهم الأكاديمية، وتكونت عينة الدراسة من ( ..؛) فرد، وأظهرت النتائج، أن التماثل مع الجامعة والأقسام كان قويًا نسبيًا، وأن التماثل مع الأقسام أقوى منه مع الجامعة، وأن مستوى التماثل للفرد يزيد بزيادة عدد سنوات الخبرة. وهدفت دراسة الصرايرة (^...r)، إلى معرفة مستوى التماثل التنظيمي لدى أعضاء هيئة التدريس في الجامعات الأردنية العامة، وتكونت عينة عشوائية من (بrT) عضوا من أعضاء هيئة التدريس، وكشفت النتائج أن مستوى التماثل التنظيمي جاء مرتفعًا. أما دراسة البشابشة (^...r) فقد هدفت للكشف عن أثر العدالة التنظيمية في التماثل التنظيمي في المؤسسات العامة الأردنية، طبقت على عينة 
مكونة من (9 (9) مفردة، وتوصلت الدراسة إلى أن تصوراهم للعدالة التنظيمية جاءت متوسطة، بينما تصوراتم لمستوى التماثل التنظيمي جاءت مرتفعة، ووجود أثر إيجابي للعدالة التنظيمية في التماثل التنظيمي، كما توجد فروق دالة إحصائيًا لتصورات المبحوثين للتماثل التنظيمي تعزى لمتغير العمر لصالح ذوي الأعمار الأعلى (vء سنة فأكثر) ،ولمتغير المؤهل العلمي لصالح ذوي المؤهلات الأعلى ( دراسات عليا)، ولمتغير الخبرة لصالح ذوي الخبرة الأعلى ( 17 سنة فأكثر)، ومتغير النوع الاجتماعي لصالح الذكور ،ومتغير المستوى الوظيفي لصالح الوظيفة الأعلى. أما دراسة الطراونة (ع (·r) هدفت إلى دراسة أثر التماثل التنظيمي في سلوك المواطنة التنظيمية في المؤسسات العامة الأردنية، وتكونت العينة من (r (ا) فردا، وتوصلت نتائج الدراسة إلى أن مستوى التماثل التنظيمي جاء مرتفعًا، كذلك وجود أثر للتماثل التنظيمي على سلوك المواطنة التنظيمية، وعدم وجود فروق ذات دلالة إحصائية في تقديرات أفراد عينة الدراسة تعزى للمتغيرات التالية (الجنس، والعمر، والمؤهل العلمي، والمستوى الوظيفي، والخبرة). وهدفت دراسة العموش (ء1.ب)، إلى معرفة درجة ممارسة عمداء الكليات لمهارات الاتصال الإداري وعلاقتها بالتماثل التنظيمي لدى أعضاء هيئة التدريس في الجامعات الأردنية الرسمية، وتكونت عينة الدراسة من (10.) عضوا من أعضاء هيئة التدريس، وتوصلت النتائج إلى وجود مستوى تماثل مرتفع، ومستوى متوسط من محارسة مهارات الاتصال الإداري، ووجود علاقة إيجابية بينهما، كما أشارت النتائج عدم وجود فروق دالة تعزى لمتغيرات: النوع، والخبرة، والكلية، وبلد التخرج. ودراسة العمري (10 •r) هدفت إلى تحديد درجة التماثل التنظيمي لدى المشرفين التربويين في محافظات شمال الأردن وعالاقته بنظام الحوافز المقدمة لمم ، وتم توزيع عينة مكونة من (· (ب) مشرف ومشرفة تربوية، وخلصت الدراسة إلى أن درجة التماثل التنظيمي لدى المشرفين التربويين متوسطة، ووجود علاقة ارتباطية بين التماثل التنظيمي والحوافز، كما أشارت النتائج وجود فروق دالة إحصائيا في مستوى التماثل التنظيمي تبعا لمتغير الخبرة لصالح الفئة المتوسطة ( 0- أقل من · ا سنوات )، ومتغير المؤهل العلمي لصالح البكالوريوس والدبلوم العالي ، ولمتغير التخصص لصالح التخصص المهني، والانساني .

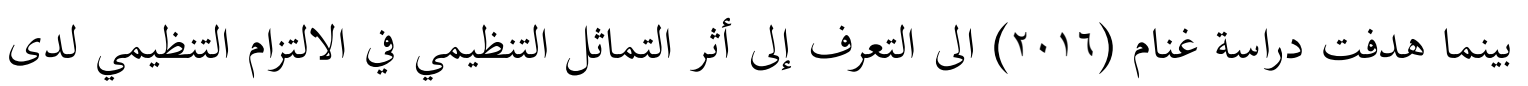
الموظفين الحكوميين في فروع الوزارات في مدينة إربد ، وتم تطبيق الدراسة على عينة عشوائية بلغت (VIV) مبحوثا من الموظفين الحكوميين، وتوصلت الدراسة إلى أن مستوى التماثل والالتزام التنظيمي جاء بدرجة 
متوسطة، وأن هناك أثرًا ايجابيًا للتماثل التنظيمي على الالتزام التنظيمي، ووجود فروق دالة إحصائيًا في تقديرات المستجيبين لمستوى التماثل تعزى : العمر لصالح من هم أكبر سنا، ومتغير الخدمة لصالح من هم أكبر خدمة، بينما لا توجد فروق دالة إحصائيًا تعزى للمتغيرات( الجنس ، والحالة الاجتماعية ، والمستوى الوظيفي، والراتب ، والمؤهل العلمي). ودراسة (ابراهيم والقتبي، VIr) هدفت إلى التعرف على درجة توافر أبعاد التماثل التنظيمي لدى العاملين في المديرية العامة للتربية والتعليم بمحافظة الظاهرة بسلطنة عمان، حيث تم تطبيق الاستبانة على عينة مكونة من (7 · (1) من العاملين بالمديرية، وتوصلت نتائج الدراسة إلى إن درجة توافر أبعاد التماثل التنظيمي لدى أفراد عينة الدراسة جاءت متوسطة، وعدم وجود فروق دالة إحصائيًا حول استجابات عينة الدراسة تعزى للمتغيرات (النوع الاجتماعي، والمؤهل العلمي، وسنوات الخبرة).

دراسة كل من السنباني والزهراء (؟1 (ب)، حيث هدفت الدراسة إلى معرفة العلاقة بين التماثل التنظيمي وبين المتغيرات الديمغرافية للعاملين في الهيئة العامة للبريد والتوفير البريدي في الجمهورية اليمنية، وتكونت العينة من (0؛ (1) موظفا من الجنسين، وتوصلت النتائج أن مستوى التماثل التنظيمي لدى العاملين جاء ضعيفًا، كما أشارت النتائج وجود فروق دالة إحصائيًا حول التماثل يعزى لمتغيرات النوع الاجتماعي لصالح الإناث، المستوى الوظيفي لصالح المستوى الأدنى، وسنوات الخبرة لصال من هم خبرقم (· (1 أقل من 10 سنة)، المؤهل العلمي لصالح أصحاب الدراسات العليا. وتناولت دراسة الجنابي (VI. r) دور التسويق الداخلي وأثره في التماثل التنظيمي لدى العاملين في المصارف الأهلية في العراق، وطبقت الدراسة على عينة تكونت من ( . .1) موظف، وسعت الدراسة إلى الكشف عن العلاقات الارتباطية والتأثيرية بين متغيري الدراسة، وكشفت النتائج عن وجود مستوى عال من التسويق الداخلي والتماثل التنظيمي ووجود علاقة ارتباطية و تأثيرية بينهما. دراسة المواضية (1) (r)، هدفت الدراسة إلى كشف أثر التماثل التنظيمي في دافعية العمل لدى مديرات رياض الأطفال من وجهة نظر المربيات في مديريات تربية الزرقاء. وتم اختيار عينة طبقية عنقودية عشوائية تكونت من (§؟§) مربية أطفال، وتوصلت الدراسة إلى وجود أثر للتماثل التنظيمي في الدافعية للعمل، وأن مستوى التماثل التنظيمي والدافعية للعمل جاء بمستوى متوسط. ودراسة ،عثماني (19) هدفت للكشف عن طبيعة العلاقة بين التماثل التنظيمي وإدراك الهوية المهنية لدى الأخصائيين النفسانيين 
في القطاع الصحي العام لولاية بسكرة، وتكونت العينة من (·r) اختصاصيًا نفسيًا، وأسفرت النتائج عن وجود علاقة ارتباطية بين التماثل التنظيمي وإدراك الهوية المهنية، ووجود مستوى عال من التماثل التنظيمي والهوية المهنية لدى أفراد العينة، كما توجد فروق دالة احصائيا في التماثل التنظيمي وإدراك الهوية المهنية تعزى لمتغير الأقدمية لصالح الأقدم، ولمتغير المؤهل العلمي لصالح حملة الليسانس والماجستير دون حملة الدكتوراه.

لذا فمن خلال الدراسات السابقة العربية والأجنبية تناول الباحثون موضوع التماثل التنظيمي في مختلف منظمات العمل، إلا أن هناك دراسات نادرة تناولت موضوع التماثل لدى المعلمين، ولم توجد دراسة عربية تناولت التماثل لدي مديري المدارس، كما تم دراسة موضوع التماثل من حيث قياس مستواه لدى الموظفين، أو من خلال ربطه ببعض المتغيرات التنظيمية كالرضا الوظيفي، والدافعية، والالتزام التنظيمي، والأداء، والمواطنة التنظيمية، والهوية التنظيمية، والعدالة التنظيمية، ويرجع السبب في الاهتمام بموضوع التماثل التنظيمي، لدوره الفاعل في تحسين مستوى أداء الأفراد وتحقيق النجاح والاستقرار للمنظمات. وفي إطار الحديث عن مشكلة الدراسة، فقد شهد العقد الأخير من القرن الماضي ظهور بعض المصطلحات أو المفاهيم التنظيمية الإدارية، نظرا لما يشهده عصرنا الحالي من تغيرات وتطورات سريعة، مما يتيح المجال أمام مختلف المنظمات ومنها المؤسسات التربوية لإجراء مراجعة شاملة لمنظومة العمل التي تتضمن الإجراءات والسياسات، إضافة إلى علاقاتما بمواردها البشرية، وما تقدمه لهم من رعاية واهتمام في مختلف الجوانب النفسية والاجتماعية والاقتصادية. وبالرغم من الجهود الكبيرة التي تبذها وزارة التربية والتعليم في سلطنة عمان لتحسين العملية التعليمية وتطويرها، إلا أن هناك بعض الدراسات التربوية العمانية أشارت إلى وجود بعض القصور لدى مديري المدارس، حيث أشارت بعض الدراسات إلى أن رضا مديري المدارس عن العملية التعليمية والإدارية في بعض المحافظات التعليمية بالسلطنة جاء متوسطاً (الغيلاني، 10ب؟؛ الناعبي، ·(·r)، وأن فاعلية المدرسة الأساسية الحكومية في سلطنة عمان في بجالي العلاقة مع المجتمع،

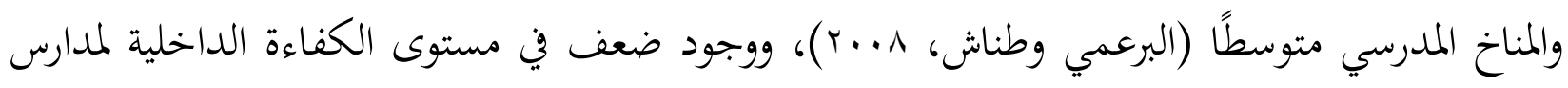
التعليم الأساسي مما أثرت سلبا في رضا المعلمين ( عيسان وآخرون، (1) ب)، كما يعد ضعف كفاءة العمل

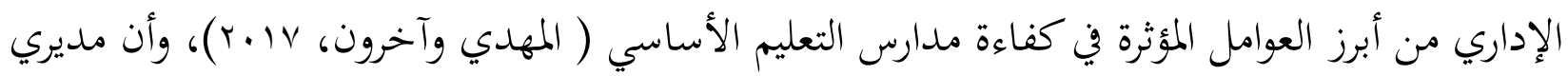
المدارس ونوابهم يمارسون أساليب وإجراءات تقليدية في الجوانب الإدارية والإنسانية، ولا يهتمون بإشراك 


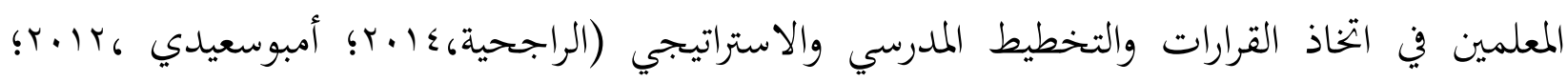
السعدي، • (·r). إضافة إلى وجود ضعف في المعرفة بصياغة رؤية ورسالة المدرسة، وإهمال تشجيع المبادرات والابداعات المدرسية، والقصور في تحديد الأهداف وأولويات العمل (اليعرب،؟با.ب). ووجود قصور في تققيق الانضباط المدرسي لدى الطلبة (المنذرية،9.+r). فيما أبدى الشقصي (11.ب) رأيه وفقًا لخبراته وبجاربه في الميدان التربوي بوجود تذمر لدى المعلمين وانخفاض دافعيتهم، وأرجع السبب في ذلك إلى اختلاف توجهات العاملين مع توجهات المسؤولين، وهذا الاختلاف قد يشير إلى عدم وجود تماثل في الرؤى والأهداف بين المعلمين والإداريين. وفيما يتعلق بموضوع التماثل التنظيمي فلم يعثر الباحث على أي دراسة تناولت هذا الموضوع لدى قيادات المدارس في البيئة التعليمية العمانية، لذا فإن هذه الدراسة سوف تبحث ما إذا كان هناك فجوة قائمة بين مديري المدارس ومؤسساتم التربوية في محافظة الظاهرة بسلطنة عمان، من خلال التعرف على مستوى تماثلهم التنظيمي مع مدارسهم، ويي ضوء ما سبق تتلخص مشكلة الدراسة في الاجابة عن التساؤلين

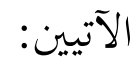

1-ما مستوى التماثل التنظيمي لدى معلمي مدارس التعليم الأساسي في سلطنة عمان؟ ץ-هل توجد فروق ذات دلالة إحصائية عند مستوى (1 (a.05) في استجابات أفراد عينة الدراسة من المعلمين تُعزى إلى متغيرات الجنس، وسنوات الخبرة، والمؤهل العلمي؟ بروك

\section{وتمدف الدراسة الحالية إلى:}

1. التعرف على مستوى التماثل التنظيمي لدى معلمي مدارس التعليم الأساسي في سلطنة عمان؟ r. استكشاف وجود فروق ذات دلالة إحصائية عند مستوى (a 1 (a) في استجابات أفراد عينة الدراسة من المعلمين تُعزى إلى متغيرات الجنس، وسنوات الخبرة، والمؤهل العلمي.

أهمية الدراسة: بالنسبة لأهمية الدراسة، فإها تتجلى في فتح بجالات بحث جديدة للباحثين العُمانيين وغيرهم من الباحثين، تتمثل بلفت انتباههم لموضوع جديد وهو التماثل التنظيمي حيث لم يهظ باهتمام كاف من قبل الباحثين التربويين خاصة في البيئة التعليمية العربية، مما قد يُساهم بِرَفد البحث العلمي بأفكار 
ونتائج جديدة تخدم الواقع العملي وتعمل على تطويره. بالإضافة إلى ذلك، فإن نتائج الدراسة الحالية قد تُشكل نواة لإجراء مزيد من الدراسات المستقبلية، بوصفها مرجعًا للباحثين والمهتمين في مجال الإدارة والسلوك التنظيمي، كما ستوفر الدراسة منصة للمسؤولين ومتخذي القرار في المستويات الإدارية العليا في الدولة بشكل عام ووزارة التربية والتعليم بشكل خاص، لاتخاذ إجراءات كفيلة بتحسين وتعزيز مستويات التماثل التنظيمي لدى المعلمين في سلطنة عمان وبحويد أدائهم، بهدف الارتقاء والنهوض بالنظام التعليمي.

\section{الإجراءات المنهجية للدراسة}

تتمثل الإجراءات المنهجية على النحو الآتي:

منهج الدراسة: اتبع الباحث في هذه الدراسة المنهج الوصفي المسحي الذي يهتم بوصف ظاهرة

أو مشكلة محددة من خلال جمع المعلومات وتحليلها وتفسيرها، بطريقة علمية دقيقة. مجتمع وعينة الدراسة: تكون بجتمع الدراسة من جميع معلمي مدارس التعليم الأساسي في بسلطنة عُمان في سبع محافظات تعليمية هي (الظاهرة، الباطنة شمال، الشرقية جنوب، ظفار، مسقط، الوسطى،

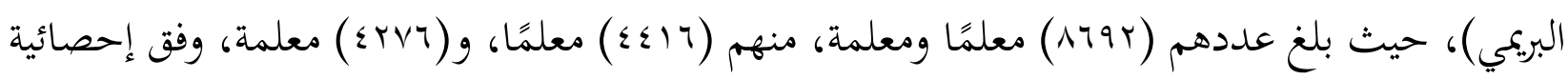

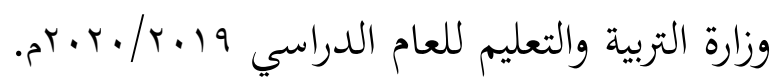

حدود الدراسة: اقتصرت الدراسة على معرفة مستوى التماثل التنظيمي لدى معلمي مدارس التعليم

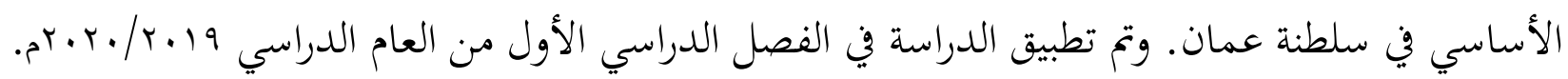
أداة الدراسة: من أجل تحقيق أهداف الدراسة قام الباحث بإعداد أداة الدراسة بعد الرجوع إلى الأدبيات والدراسات السابقة التي بكثت في مجال التماثل التنظيمي، مثل (cheney,1982)، وترجمها بعض الباحثين

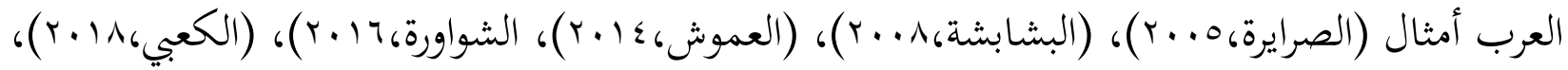
حيث تكونت الاستبانة من (rr) فقرة بعد التحكيم، موزعة على ثلاثة مجالات رئيسة. صدق الأداة: للتحقق من صدق الأداة قام الباحث بعرضها إلى مجموعة من المحكمين ذوي الخبرة والتخصص في بجال الإدارة التربوية، حيث بلغ عددهم (1) محكمًا من أعضاء هيئة التدريس العاملين في بعض المؤسسات التعليمية من داخل السلطنة مثل جامعة نزوى، وجامعة صحار، وجامعة السلطان قابوس، وجامعة كفر الشيخ من جمهورية مصر العربية، حيث أبدى المككمون ملاحظاهم ومقترحاقم حول عبارات 
الأداة مثل التدقيق اللغوي، وبعد إجراء التعديلات المطلوبة أصبحت الأداة جاهزة وملائمة لقياس أبعاد التماثل التنظيمي والمكونة من (rr) عبارة.

ثبات الأداة: قام الباحث استخدام معامل ألفاكرو نباخ، لاستخراج معامل الثبات لأداة الدراسة بشكل عام، حيث تم تطبيق الأداة على عينة (•r) خارج عن نطاق عينة الدراسة الأصلية، ويتضح من الجحدول رقم (r) أن الاستبانة تتمتع بمعامل ثبات عال بلغ (90,.•)، وتراوحت معاملات ثبات محاور

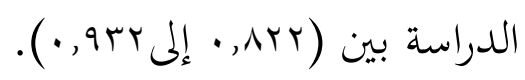

جدول(1) معاملات الثبات نماور الدراسة والخور الكلي

\begin{tabular}{|c|c|c|c|}
\hline معامل الثبات & عدد الفقرات & الخحور & p \\
\hline •,NMI & $\wedge$ & الولاء & 1 \\
\hline$\cdot, \lambda Y r$ & v & التشابه & r \\
\hline • & $\wedge$ & الانتماء & $r$ \\
\hline$\cdot 90$. & rr & \multicolumn{2}{|c|}{ المحور الكلي } \\
\hline
\end{tabular}

توزيع الاستبانة: تم توزيع (.... استبانة على المعلمين والمعلمات في المحافظات المستهدفة، وبما أن الباحث استخدم العينة الطبقية العشوائية، فقد تم توزيع الاستبيان بموجب نسبة عدد المعلمين والمعلمات في كل محافظة نسبة إلى إجمالي حجم العينة، حيث تم استرجاع (. (^) استبانة، أما الاستبانات الغير مسترجعة بلغت (•؛ () استبانة، واستبعاد (ع () استبانة نظرًا لعدم صلاحيتها للتحليل الإحصائي، لذا فإن العدد الصالح لإجراء التحليلات الإحصائية والذي يمثل عينة الدراسة بلغ (؟؟^) استبانة، تشكل ما نسبته

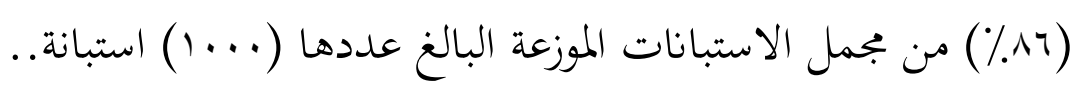
الوزن النسبي: وتسهيلا لعرض نتائج الدراسة وتفسيرها، فقد تم تصنيف المتوسطات الحسابية وفقا لمعيار ليكرت الخماسي، بحيث تضمنت درجة الموافقة خمسة مستويات هي (غير موافق بشدة، غير موافق، محايد، موافق، موافق بشدة)، كما تم استخراج المتوسطات الحسابية والتقديرات حسب التصنيف الآتي: - المتوسط الحسابي الذي يقع بين ( - r r,rr) مؤشرًا منخفضًا (قليل) 


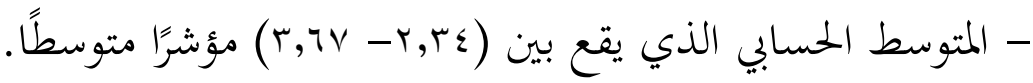

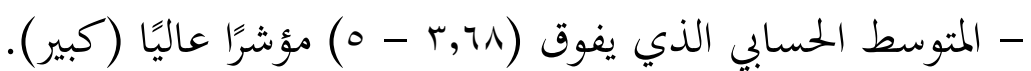

\section{نتائج الدراسة ومناقشتها}

أولاً: السؤال الأول: ما مستوى التماثل التنظيمي لدى معلمي مدارس التعليم الأساسي في سلطنة

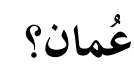

يوضح الجدول رقم (r) المتوسطات الحسابية والانحرافات المعيارية لمحاور الدراسة الثلاثة مرتبة ترتيبا

تنازليا حسب المور الأكبر قيمة بالمتوسط الحسابي.

الجدول (ץ): المتوسطات الحسابية والانحرافات المعيارية لمحاور البحث

\begin{tabular}{|c|c|c|c|c|}
\hline درجة الموافقة & الرتبة & الانخراف المعياري & المثتوسط الحسابي & الخور \\
\hline عالية & 1 & .696 & 3.978 & الالتماء \\
\hline عالية & 2 & .698 & 3.901 & الولاء ل ملاء \\
\hline عالية & 3 & .663 & 3.818 & التشابه \\
\hline عالية & & .623 & 3.899 & المحور الكلي \\
\hline
\end{tabular}

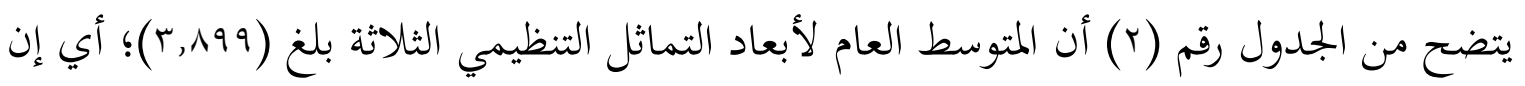
تصورات أفراد عينة البحث من معلمي مدارس التعلم الأساسي في سلطنة عمان جاءت بمستوى مرتفع، وبالرجوع إلى مستويات أبعاد التماثل التنظيمي نجد أن بُعد الانتماء التنظيمي يأتي في المرتبة الأولى، بمتوسط

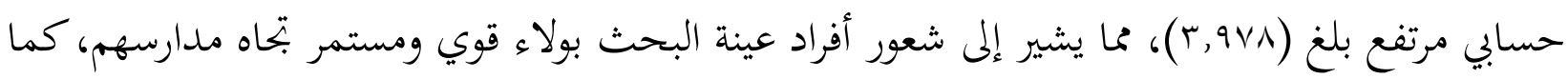
يشعرون بالفخر بتاهها، ولديهم الرغبة القوية والاستعداد لتسخير إمكانياقم لبذل جهود كبيرة من أجل تققيق أهداف مدارسهم، إذ يرون أن مستقبلهم الشخصي مرتبط بمستقبل مدارسهم، مما يدفعهم إلى الحمديث الإيجابي عن مشاريع مدارسهم وإنجازاها، والتفاخر بها بين أفراد المجتمع المحيط، والمحافظة بقدر الإمكان على سمعتها الإيجابية، ومحاولة التضحية والدفاع عنها قدر الإمكان، ويدل مستوى الانتماء 
التنظيمي لدى أفراد عينة البحث؛ على وجود تماثل تنظيمي إيجابي، وهذا يشير إلى نوع من التوافق والارتباط النفسي والاجتماعي بين المعلم والمدرسة، ويعد عاملاً مهمَّا في تحقيق بعض السلوكيات الإيجابية في بيئة العمل التربوي من مثل الالتزام، والتعاون، والإخلاص، والأداء، وسلوكيات المواطنة التنظيمية وغيرها من السلوكيات التي قد تؤدي إلى زيادة كفاءة المؤسسة التربوية، ويدل ذلك أيضًا على الشعور بأهمية التماثل التنظيمي، وأنه من المواضيع السلوكية والإدارية المهمة لتحقيق النجاح للمعلمين ولمؤسساتم التربوية. وتتفتق

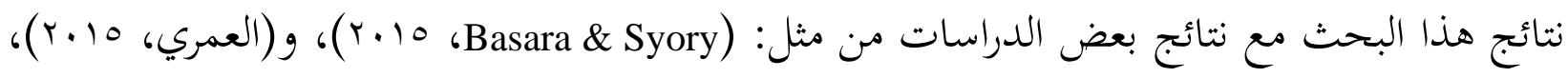

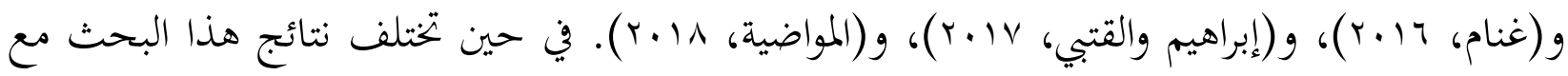

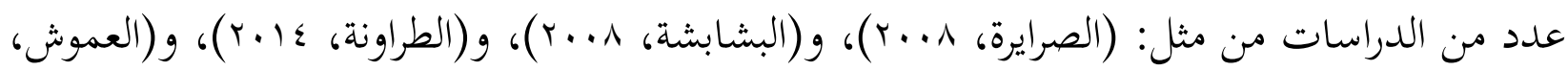

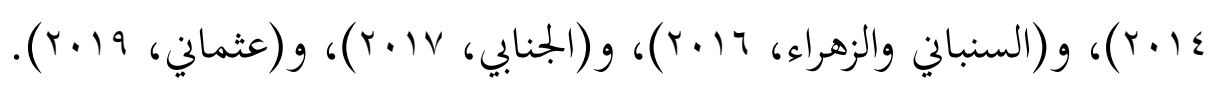

السؤال الثاني: هل من فروق دالة إحصائيَّا عند مستوى (ه.. •) في استجابات أفراد عينة

البحث من معلمي مدارس التعليم الأساسي تُعزى إلى متغيرات: النوع، والمؤهل العلمي، والحبرة؟ متغير النوع: للإجابة عن هذا السؤال تم استخدام اختبار "ت" للعينات المستقلة، ويتضح من الجدول رقم (r) وجود فروق دالة إحصائيًّ بين استجابات أفراد عينة البحث من الذكور والإناث في كل محاول التماثل التنظيمي (الولاء، الانتماء، التشابه) وكل هذه الفروق هي لصالح الأناث؛ إذ إن متوسطهن

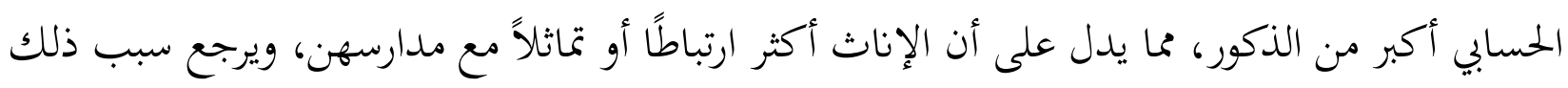
إلى أهن يرين هذه المهنة موضوع استقرار وظيفي لهن، وأها الأنسب مقارنة بالوظائف الأخرى بحكم أن بيئة العمل تتضمن في مجملها موظفات فقط، إضافة إلى شعور المعلمة بأها تستمد مكانتها الاجتماعية من خلال موقعها الوظيفي، وأها تشعر بالرضا عن بعض جوانب العمل، وهذا يزيد من مستوى تماثلهن مع المدارس، ورغبتهن في الاستمرار والبقاء في العمل، كما يدفعهن التماثل مع مدارسهن إلى العمل على بلى تحقيق أهداف المدرسة. وتتفق هذه النتيجة مع نتيجة دراسة (السنباني والزهراء، 14 .بr)، وتختلف مع نتائج

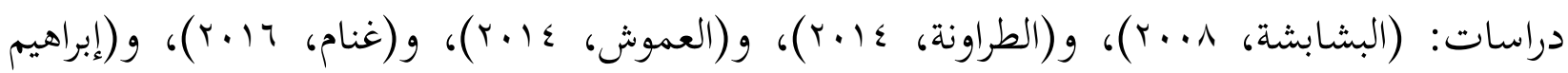

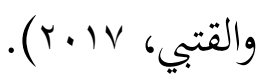


جدول (r) الفروق الإحصائية في التماثل التنظيمي للمعلمين وفق متغير النوع الاجتماعي

\begin{tabular}{|c|c|c|c|c|c|c|c|}
\hline مستوى الدلالة & قالإحصائية الدلالة & قمة "ت" & الالمعراف & المتوسط & العدد & النوع & الخور \\
\hline إحصائياً &., .19 & $-r$, TOT & $\begin{array}{l}\text { TVE. } \\
V 17 .\end{array}$ & $\begin{array}{l}r, \wedge \varepsilon \varepsilon \\
r, 90 \vee\end{array}$ & $\begin{array}{l}\text { हाq } \\
\varepsilon r V\end{array}$ & أناث & الولاء \\
\hline إحصائياً & $\cdot, \ldots \varepsilon$ & $-r, \wedge q \varepsilon$ & $\begin{array}{l}7 V 7 . \\
V .9 .\end{array}$ & $\begin{array}{l}r, q \cdot \wedge \\
\varepsilon, \cdot \leq \tau\end{array}$ & $\begin{array}{l}\text { ध19 } \\
\varepsilon r V\end{array}$ & أناث & الانتماء \\
\hline إحصائياً & $\cdot, .19$ & - & $\begin{array}{l}\text { Tsl. } \\
\text { TVO. }\end{array}$ & $\begin{array}{l}r, V r r \\
r, q .1\end{array}$ & $\begin{array}{l}\sum 19 \\
\varepsilon r V\end{array}$ & ذأناث & التشابه \\
\hline إحصائياً & $\cdot, .19$ & $-r, r \wedge O$ & $\begin{array}{l}\text { OqY. } \\
7 \varepsilon .\end{array}$ & $\begin{array}{l}r, \lambda r \wedge \\
r, 9 T \wedge\end{array}$ & $\varepsilon r V$ & أناث & الملي \\
\hline
\end{tabular}

المؤهل: توضح نتائج تحليل التباين الإحادي (One Way ANOVA) في الجدول رقم (ع) عدم وجود فروق ذات دلالة إحصائيًّا في مستوى التماثل التنظيمي لدى أفراد عينة الدراسة وفق متغير المؤهل العلمي (دبلوم، البكالوريوس، الدراسات العليا)، وتتفق هذه النتيجة مع نتائج دراسات: (الطراونة، ـ (ب))،

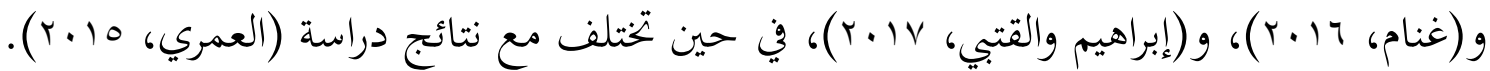




\begin{tabular}{|c|c|c|c|c|c|c|c|}
\hline مستوى الدلالة & قالإحصة & قمة "ت" & الانحراف & المتوسط الحسابي & العدد & المؤهل & الخور \\
\hline \multirow{3}{*}{ غير دال } & $\cdot, .77$ & \multirow{3}{*}{$r, V r}$. & $V \cdot r$. & $r, \wedge r \tau$ & IAT & دبلوم & \\
\hline & & & TA^. & $r, 94 \tau$ & $7 . r$ & بكالوريوس & الولاء \\
\hline & & & vo9. & $r, v \wedge l$ & 71 & ماجستير & \\
\hline \multirow{3}{*}{ غير دال } & • & \multirow{3}{*}{$1, \pi 7 V$} & T9Y. & $\Gamma, \wedge \vee \wedge$ & 111 & دبلوم & \\
\hline & & & $7 \wedge \Lambda$. & $\varepsilon, .19$ & $7 . r$ & بكالوريوس & الانتما \\
\hline & & & vor. & $r, \wedge \uparrow q$ & 71 & ماجستير & $s$ \\
\hline \multirow{3}{*}{ غير دال } & $\cdot, r \vee \leqslant$ & \multirow{3}{*}{$1, r 97$} & 709. & $r, \lambda) \leqslant$ & 111 & دبلوم & \\
\hline & & & 701. & $r, \lambda r r$ & $7 . r$ & بكالوريوس & \\
\hline & & & VAl. & $r, 7 \wedge q$ & 71 & ماجستير & ابه \\
\hline \multirow{3}{*}{ غير دال } & $\cdot, \cdot \times 1$ & \multirow{3}{*}{ ץ,T. } & $T r \varepsilon$. & $r, \wedge \uparrow q$ & $11 \mathrm{r}$ & دبلوم & \\
\hline & & & 711. & $r, q r q$ & $7 . r$ & بكالوريوس & العحور \\
\hline & & & $v) \leq$. & $r, \vee \vee q$ & 71 & & \\
\hline
\end{tabular}

سنوات الحبرة: توضح نتائج تحليل التباين الإحادي (One Way ANOVA) في الجدول رقم (0) عدم وجود فروق ذات دلالة إحصائيَّا في مستوى التماثل التنظيمي لدى أفراد عينة الدراسة وفق متغير سنوات الخبرة التدريسية للمعلمين. وتتفق هذه النتيجة من جهة مع نتيجة دراسات: (رشيد، ب...r)،

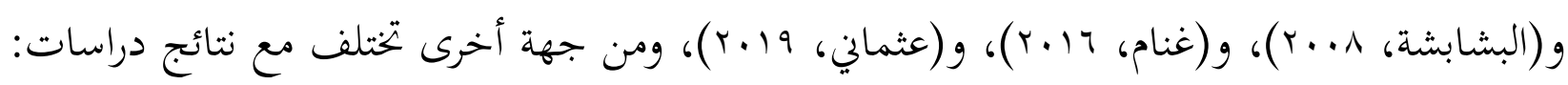

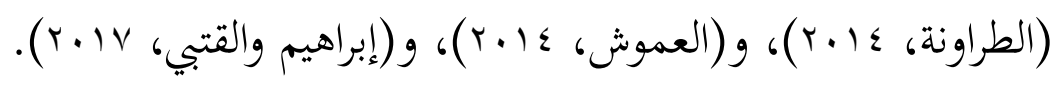


جدول (0) الفروق الإحصائية في التماثل التنظيمي للمعلمين وفق متغير سنوات الخبرة التدريسية

\begin{tabular}{|c|c|c|c|c|c|c|c|}
\hline مستوى الدلالة & قالإحصة الدلالة & قمة "ت" & الانمراف & المتوسط & العدد & الحبرة & الخور \\
\hline \multirow{4}{*}{ غير دال إحصائياً } & $\cdot, r 99$ & -, 499 & $V \leqslant 0$. & $r, q \leq q$ & 117 & 1-ه سنوات & \multirow{4}{*}{ الولاء } \\
\hline & & & $T V \cdot$. & $r, \wedge \wedge r$ & rar & צ-· اسنوات & \\
\hline & & & vio. & $r, 9) \leqslant$ & 197 & 11 -0 |سنة & \\
\hline & & & 797. & $r, \wedge \wedge q$ & $r \leqslant 1$ & أكثر من 10 & \\
\hline \multirow{4}{*}{ غير دال إحصائياً } & •, 97V & $\cdot, 97 \mathrm{~V}$ & V1. & $r, 910$ & 117 & 1-0 سنوات & \multirow{4}{*}{ الانتماء } \\
\hline & & & $T \varepsilon$. & $r, q \leq \vee$ & rar & צ- · اسنوات & \\
\hline & & & vor. & $\varepsilon, \cdot r q$ & 197 & |1-0 اسنة & \\
\hline & & & 799. & $\varepsilon, \ldots \varepsilon$ & $r \leqslant 1$ & أكثر من 10 & \\
\hline \multirow{4}{*}{ غير دال إحصائياً } & . & . & VTr. & $r, 107$ & 117 & 1-ه سنوات & \multirow{4}{*}{ التشابه } \\
\hline & & & . & $r, A r V$ & rar & צ- • اسنوات & \\
\hline & & & 770. & $r, \lambda \cdot r$ & 197 & |1-0-1 اسنة & \\
\hline & & & $T V \varepsilon$. & r, .१৭ & $r \leqslant 1$ & أكثر من 10 & \\
\hline \multirow{4}{*}{ غير دال إحصائياً } & $\cdot, .90$ & $\cdot, .90$ & . & $r, q \cdot v$ & 117 & 1-0 سنوات & \multirow{4}{*}{ الكلي } \\
\hline & & & 070. & $r, \wedge \wedge \uparrow$ & rar & 7- • اسنوات & \\
\hline & & & $70 \leqslant$. & $r, 910$ & 197 & |1-0-1 اسنة & \\
\hline & & & $7 \leqslant 7$. & 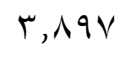 & $r \leqslant 1$ & أكثر من 10 & \\
\hline
\end{tabular}

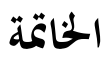

يعد التماثل التنظيمي من المواضيع الإدارية المهمة التي تناولتها مؤخرًا الدراسات والبحوث العربية، ويأتي الاهتمام بهذا الموضوع من منطلق تعزيز ارتباط الأفراد بمؤسساقم وجوانب عملهم، مما يزيد من فاعلية العمل وتحقيق أهداف المؤسسات ومنها المؤسسات التربوية، وفي هذا السياق، تناول البحث الحالي مستوى التماثل التنظيمي لدى معلمي مدارس التعليم الأساسي في سلطنة عمان، باعتباره موضوعًا مهمًا، فتماثل المعلمين

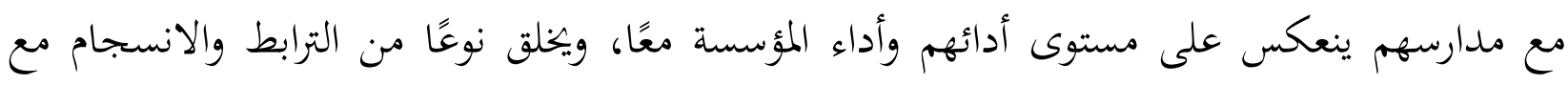
المعلمين أنفسهم من جهة، ومع المدرسة من جهة أخرى. ولتعزيز مستوى التماثل في المؤسسات التربوية 
وبناء على النتائج التي توصلت إليها هذه الدراسة، فمن المناسب اقتراح بعض التوصيات التي تساعد المسؤولين التربويين على تعزيز مستوى التماثل التنظيمي لدى المعلمين، ومن بين هذه التوصيات: ا-تعميق الوعي لدى المعلمين حول بعض المفاهيم السلوكية الحديثة كمفهوم التماثل التنظيمي، ونشر ثقافته وسط الحقل التربوي، حيث يعد موضوع التماثل التنظيمي أحد المتغيرات التنظيمية التي تسهم في تعزيز كثير من السلوكيات الإيجابية في بيئة العمل كالالتزام والأداء والدافعية والرغبة في الاستمرارية في العمل. ץ-منح المعلمين فرص المشاركة في اتخاذ القرارات التربوية مما يؤدي إلى شعورهم بالاهتمام من جانب المسؤولين، وهذا يدفعهم إلى الاندماج والارتباط مع مدارسهم والعمل على تحقيق أهدافها. ب-الاهتمام بتعزيز العلاقات الإنسانية بين المعلمين من جهة وبينهم وبين المسؤولين من جهة أخرى، من خلال نشر ثقافة العمل المشترك، وتنظيم اللقاءات الدورية مما يتيح الفرصة لتبادل الآراء والمقترحات ومناقشة الأعمال التربوية بكل شفافية ووضوح. ع -إجراء تطوير في نظام الأجور والحوافز المادية والمعنوية لدى المعلمين لإشباع احتياجاهم ورغباقم المختلفة، وهذا يعزز من مكانتهم الاجتماعية ومن ثم زيادة مستوى تماثلهم مع مدارسهم. ه-تحفيز المعلمين المجيدين في بجال التدريس، وأصحاب المبادرات التربوية، وهذا يعزز من مستوى ارتباطهم بمدارسهم، ويتولد لديهم شعور بالرغبة في البقاء والاستمرارية في العمل. 7- الاهتمام بتطوير مهارات المعلمين، وتعزيز خبراتم من خلال البرامج التدريبية المهنية المستمرة، والمشاركة في المؤتمرات، والندوات، واللقاءات التربوية المختلفة، حيث تساعد هذه البرامج في الشعور بالمسؤولية، والقدرة على تقديم أداء تدريسي جيد، مما يزيدهم ارتباطا وتماثلا مع مدارسهم. V-إجراء مزيد من المسوحات حول موضوع التماثل التنظيمي لدي الموظفين التربويين العاملين في وزارة التربية والتعليم في السلطنة، لتشخيص مستوى تماثلهم التنظيمي، والتعرف على احتياجاتم ورغباتم، وكذلك دراسة التماثل التنظيمي وربطه ببعض المتغيرات التنظيمية مثل الهوية التنظيمية، دوران العمل، الالتزام 


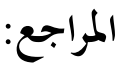

السعدي، عصرية بنت ضاوي بن صالح. (·(بrم). متطلبات تطبيق التخطط الاستراتيجي في مرحلة التعليم العام بسلطنة عمان، رسالة ماجستير، معهد البحوث والدراسات العربية، القاهرة.

العاني، آلاء عبد والبكري، حلى حكمت الموجود. (V (r.م)." إسهامات القيادة التشاركية في تحقيق التماثل

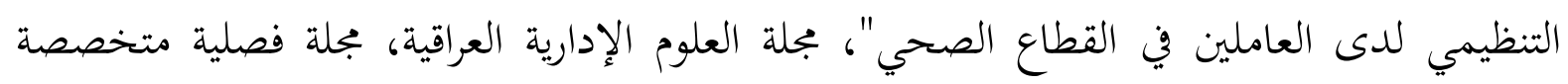

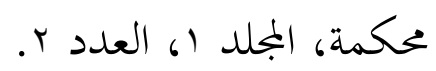

اليعربي، علي بن سيف بن سعود. (rا ·rم). مشكلات التخطيط الاستراتيجي في مدارس التعليم الأساسي

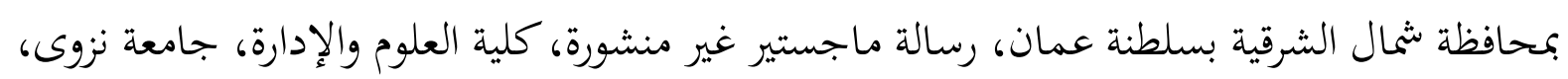

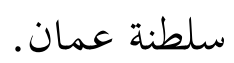

الأمبوسعيدية، منى بنت محمد بن سلام. (r (rTم). تطوير إدارة مدارس التعليم الأساسي في ضوء مدخل

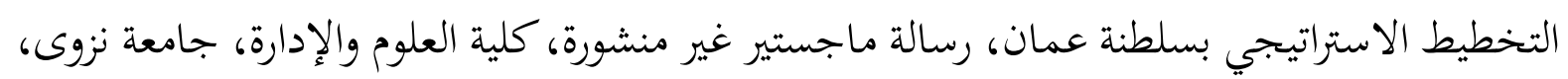

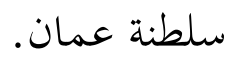

المنذرية، ميمونة بنت سالم بن سعيد. (9..+r). معوقات تحقيق مديري المدارس للانضباط المدرسي لدى الطلاب في سلطنة عمان من وجهة نظرهم، كلية التربية، جامعة السلطان قابوس، سلطنة عمان.

إبراهيم، حسام الدين والقتبي، محمد بن راشد. (V V.rم). درجة توافر أبعاد التماثل التنيمي لدى العاملين

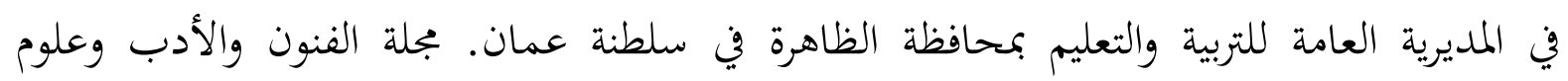

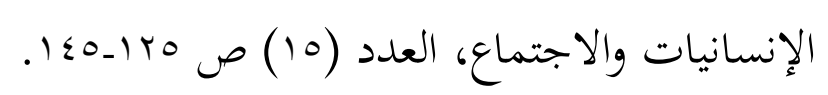

البشابشة، سامر عبد المجيد. (^. rام). أثر العدالة التنظيمية في بلورة التماثل التنظيمي في المؤسسات الأردنية

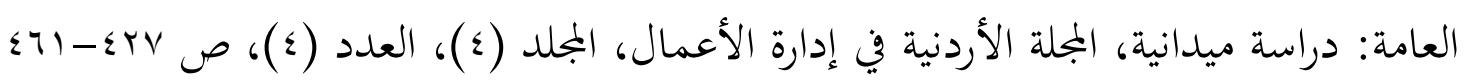


الزعبي، خلود فواز. (rا •rم). درجة ممارسة مديري المدارس الخاصة في عمان العاصمة لأبعاد القيادة التحويلية وعلاقتها بالتماثل التنظيمي من وجهة نظر المعلمين. رسالة ماجستير. قسم العلوم الاجتماعية، كلية

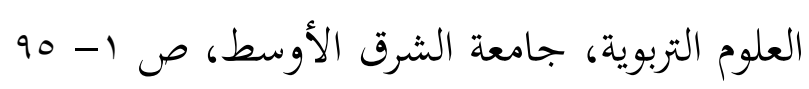

لشواورة، طه سالم. (17.بم). أثثر التماثل التنظيمي في دافعية العمل لدى وزارة التربية والتعليم الأردنية في مديرية التربية والتعليم لقصبة الكرك. مجلة الجامعة الإسلامية للدراسات الاقتصادية والإدارية، المجلد المبل

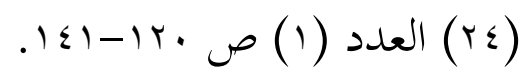

الصرايرة، خالد أحمد سلامة. (0.rم). التماثل التنظيمي لأعضاء الميئات التدريسية في الجامعات الأردنية الرسمية وعلاقته بشعورهم بالأمن وبأدائهم الوظيفي. رسالة دكتوراه، كلية الدراسات التربوية العليا،

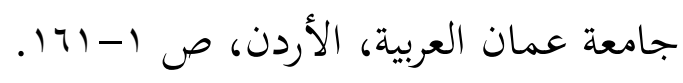
العموش، آية خالد محمد. (ع ا بـم). درجة ممارسة عمداء الكليات لمهارات الاتصال الإداري وعلاقتها بمستوى التماثل التنظيمي لدى أعضاء هيئة التدريس في الجامعات الأردنية الرسمية. عمادة البحث العلمي

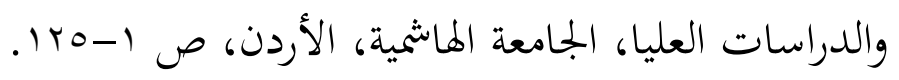

غنام، إسيل عبد الرحن. (ד • rم). أثر التماثل التنظيمي في الالتزام التنظيمي لدى الموظفين الحكوميين في

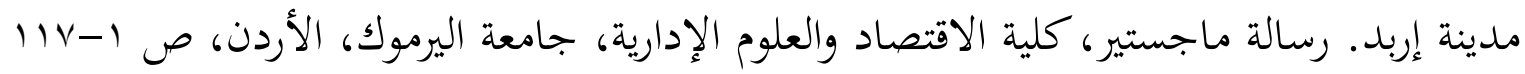
الفتلاوي، ميثاق هاتف وفاضل، علاء حسين وعبد اليمه، عادل بجيد. (10 •rم). دور الاحترام الداخلي المدرك في التماثل التنظيمي بحث تحليلي في كليات جامعة كربلاء، بجلة الإدارة والاقتصاد، المجلد

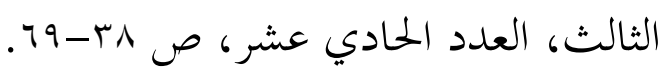

السنباني، عامر عبد الوهاب والزهراء، مهديد فاطمة. (7 (بrم). التماثل التنظيمي وعلاقته بالمتغيرات الديموغرافية دراسة ميدانية على الهيئة العامة للبريد والتوفير البريدي في الجمهورية اليمنية. مجلة إدارة

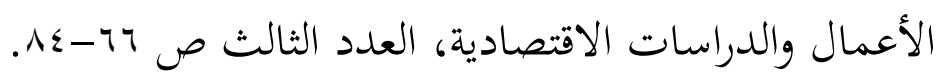
العمري، إسلام. (10 بام). التماثل التنظيمي لدى المشرفين التربويين وعلاقته بنظام الحوافز المقدم لهم، رسالة

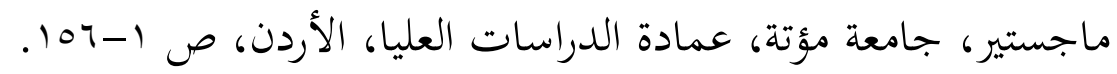


الصرايرة، خالد أحمد. (^. .rم). التماثل التنظيمي لدى الهيئات التدريسية في الجامعات الأردنية العامة، مجلة

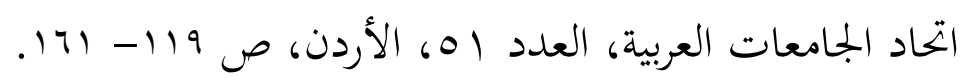

الطراونة، مروان عقل حمود. (ع ا.بr). أثر التماثل التنظيمي في سلوك المواطنة التنظيمية في المؤسسات العامة الأردنية من وجهة نظر العاملين - دراسة تطبيقية-رسالة ماجستير، عمادة الدراسات العليا، جامعة

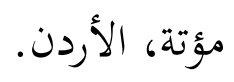

الزغلوان، معتصم ياسين محمد. (ع ا بrم). "النمط القيادي في ظروف عدم التأكد وأثره على التماثل التنظيمي: دراسة تطبيقية على القطاع الحكومي في المملكة الأردنية الهاشمية"، رسالة دكتوراه، جامعة العلوم

$$
\text { الإسلامية العالمية، الأردن. }
$$

الكعبي، حميد سالم. (1/ +rم). دور التماثل التنظيمي في الحد من الصمت التنظيمي (دراسة استطلاعية لآراء عينة من الموظفين في المصارف العراقية الأهلية/بغداد). مجلة جامعة الانبار للعلوم الاقتصادية والادارية

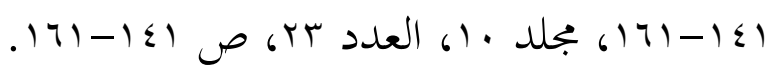

المواضية، رضا سلامة. (11 •rم) أثر التماثل التنظيمي في دافعية العمل لدى مديرات رياض الأطفال من وجهة

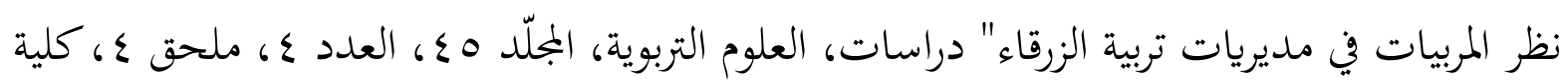

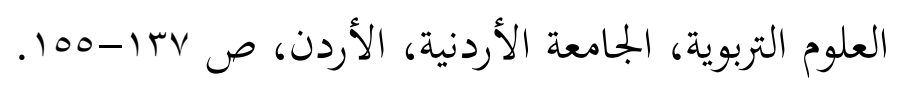

عثماني، صوريا. (19 • rم). " التماثل التنظيمي وعلاقته بإدراك الهوية المهنية عند الأخصائي النفسي في القطاع

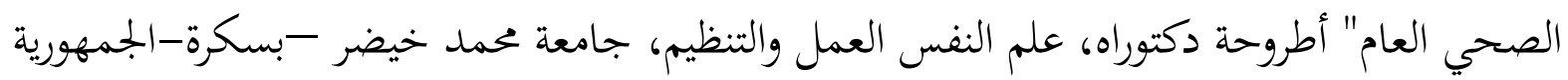

الجزائرية الديمقراطية الشعبية.

الجنابي، سنان عليوي عباس والجنابي، حسين علي عبد الرسول والموسوي، مرتضى طعمة سلطان (V V † Tم). دور التسويق الداخلي في تعزيز التماثل التنظيمي: دراسة تحليلية في المصارف الأهلية في محافظة بابل،

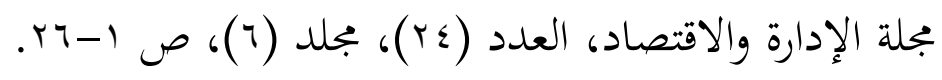


رشيد، مازن فارس. (r. .rم). الهوية التنظيمية والتماثل التنظيمي: تحليل للمفهوم والأبعاد السلوكية التطبيقات. مركز البحوث - كلية العلوم الإدارية، جامعة الملك سعود، دار النشر العلمي والمطابع، الرياض.

الشقصي، سعيد بن عبد الله بن ناصر. (1/ (rم). فاعلية التشريعات التعليمية في توجيه المناخ التنظيمي في المؤسسات التعليمية في سلطنة عمان، رسالة ماجستير، جامعة نزوى، سلطنة عمان.

الغيلاني، صبحة بنت سالم بن حليس. (10 •rم). درجة ممارسة المشرفين الإداريين لإبعاد إدارة التغيير وعلاقتها بالرضا الوظيفي لمديري المدارس ومساعديهم، بمحافظة جنوب الشرقية في سلطنة عمان، رسالة ماجستير، جامعة نزوى، سلطنة عمان.

الناعبي، ناصر بن حمدان بن سعيد. (•(بrم). الولاء التنظيمي وعلاقته بالرضا الوظيفي لدى مديري مدارس الحلقة الثانية من التعليم الأساسي في سلطنة عمان، رسالة ماجستير، جامعة نزوى، سلطنة عمان.

الراجحية، شريفة بنت عبدالله بن زهران. (عا •rم). درجة ممارسة مديري مدارس التعليم ما بعد الأساسي لمهارات تقويم الأداء الوظيفي من وجهة نظر المعلمين بمحافظة الداخلية في سلطنة عمان. رسالة ماجستير، جامعة نزوى، سلطنة عمان.

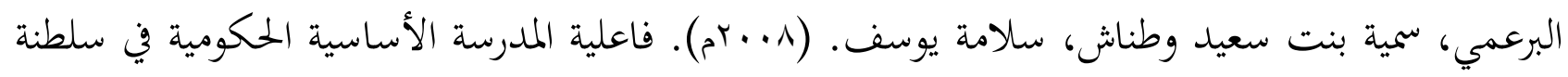
عمان من وجهة نظر المشرفين والمديرين والمعلمين، دراسات العلوم التربوية، المجلدهب، العدد ا. .

المهدي، ياسر فتحي الهنداوي والفهدي، راشد بن سليمان ولاشين، محمد عبد الحميد والسعيدي، محمد

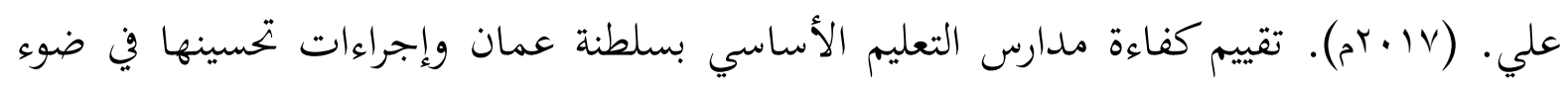
مدخل الكفاءة النسبية. المجلة الدولية التربوية المتخصصة، المجلد جا، العدد (؟)، جامعة المبه السلطان قابوس.

Ashforth, B. E., \& Mael, F. (1989). Social identity theory and the organization. Academy of management review, 14(1), 20-39.

Basar, Ufuk; Sýðrý, Ünsal. (2015). Effects of Teachers' Organizational Justice Perceptions on Intention to Quit: Mediation Role of Organizational Identification, Educational Sciences: Theory \& Practice, 15(1), 45-59. 
Cheney, G. 1983a. On the various and changing meanings of organizational membership: A field study of organizational identification. Communication Monographs, 50: 342-362

El-Kassar, A. N., Makki, D., \& Gonzalez-Perez, M. A. (2019). Student-university identification and loyalty through social responsibility: A cross-cultural analysis. International Journal of Educational Management, 33(1), 45-65.

Johnson, W. L., Johnson, A. M., \& Heimberg, F. (1999). A primary-and second-order component analysis of the organizational identification questionnaire. Educational and psychological measurement, 59(1), 159-170.

Krso. A (2017). Construed External Image and Organizational Identification in a Virtual Workplace. Master's Thesis, Lunds University, Department of Psychology, Sweden

Mete, E. S., Sökmen, A., \& Biyik, Y. (2016). The relationship between organizational commitment, organizational identification, person-organization fit and job satisfaction: A research on IT employees. International Review of Management and Business Research, 5(3), 870

Patchen, M. 1970. Participation, achievement, and involvement on the job. Englewood Cliffs, NJ: Prentice-Hall 